\title{
Development of four quadrant operation of DC to DC converter using single phase matrix converter
}

\author{
Rahimi Baharom, Abdul Muin Awang \\ Faculty of Electrical Engineering, Universiti Teknologi MARA, Malaysia
}

\begin{tabular}{l}
\hline \hline Article Info \\
\hline Article history: \\
Received Apr 8, 2019 \\
Revised Jun 10, 2019 \\
Accepted Jul 22, 2019 \\
\hline
\end{tabular}

\section{Keywords:}

Commutation problem

DC to DC converter

Four-quadrant operation

Single-phase matrix converter

\begin{abstract}
Single-Phase Matrix Converter (SPMC) is an advanced circuit topology that offer advantages such as the capability to regenerate energy back to the input, sinusoidal input and output current and a manageable input current displacement factor. By considering the opportunity of an advanced SPMC topology, further exploration on DC to DC operation is proposed. The fourquadrant operation of switching algorithm was developed to control the SPMC circuit. The voltage and current profile of each quadrant was investigated to validate the proposed switching control algorithm. As part of four quadrants DC to DC operation, the safe commutation switching algorithm was also developed in order to solve the commutation problem due to the used of an inductive load. The pulse width modulation (PWM) techniques was utilized to synthesize the output of the proposed converter. Results from MATLAB/Simulink are presented to validate the proposed circuit operation.
\end{abstract}

Copyright $@ 2019$ Institute of Advanced Engineering and Science. All rights reserved.

\section{Corresponding Author:}

Rahimi Baharom,

Faculty of Electrical Engineering,

Universiti Teknologi MARA,

40450 Shah Alam, Selangor, Malaysia.

Email: rahimi6579@gmail.com

\section{INTRODUCTION}

DC to DC converter are widely used in various applications required controlled DC supply used for traction motor control in electric automobile and portable equipment that is not connected direct to the supply utility. Among the advantage of DC to DC converter is the output can be configured to be either positive or negative values or floating ground for various applications. It has noise and interference blocking capability hence offer the load with a cleaner DC supply that is needed by several sensitive loads [1].

Conventional DC to DC converter circuit required additional circuit in order to control four quadrant operations of DC machines [2]. This conventional circuit can contribute to the low power density and resulting in high power loss that could lead to low efficiency problem $[1,3,4]$.

In this work, advanced DC to DC converter based on SPMC topology is proposed. This stabilizing controller has a lot of advantages such as could perform four quadrant operations by only using a single converter as compared to the conventional converter that requires additional circuit converter such as dualconverter. Thus, the proposed DC to DC converter can minimize the cost, reduce power loss and increase power density of the power supply system. As part of DC to DC converter operation, the switching algorithm for safe-commutation technique was proposed to avoid voltage and current spikes due to the used of inductive load. Selected simulation results are presented to verify the proposed operations. 


\section{SINGLE-PHASE MATRIX CONVERTER}

Matrix Converter (MC) is an array of bidirectional switches as the main power elements, which interconnects directly the input supply to the load, without using any DC-link or large energy storage elements. The MC is able to remove the need for reactive energy storage component used in conventional rectifier-inverter based systems. MCs offer many advantages over traditional topologies, such as the ability to regenerate energy back to the utility, sinusoidal input and output currents and a controllable input current displacement factor $[5,6]$.

The SPMC topology is as shown in Figure 1. It consists of input and output lines with four bidirectional switches which capable in conducting current in both directions, whilst at the same time blocking forward and reverse voltages [7-9]. SPMC is as advance circuit that can be implementing in any type of converter depends on the topology. It can be run either inverter or converter depend on the controlled switching algorithm. The bidirectional switch involves of anti-parallel IGBTs with diode pairs [10-14] as shown in Figure 2, allowing current to flow in both directions.

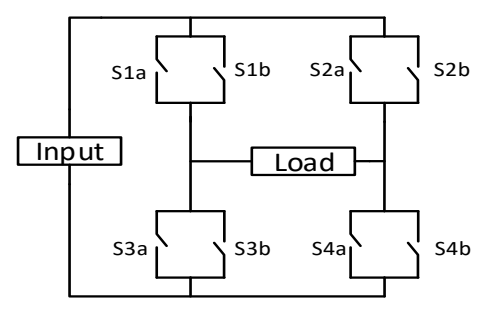

Figure 1. SPMC circuit topology

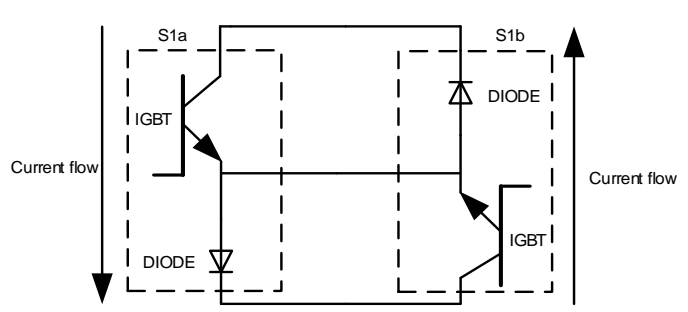

Figure 2. Common Emitter Antiparallel IGBT with diode pairs

\section{COMMUTATION PROBLEM}

The most common problem in matrix converter is commutation, that could lead to voltage or current spikes due to the used of inductive load. It occur during switches turn 'OFF' and hence the existence of possible reverse current [7]. There is serious issues related to the control of four quadrant switches; neither dead-time nor conduction overlap is allowed once the two switches commutate the inductive load current. In matrix converter, there is no free-wheel paths, so the load current have to be compelled to be safely commutated with numerous methods [15-25]. Another issues associated with commutation problem is the finite switching times and propagation delays of devices when using the semiconductor switches resulting with possible short circuit. As a results, the safe-commutation strategy must be keep in mind when utilise with the SPMC topology.

\section{FOUR QUADRANT OPERATION}

Figure 3 shows the voltage and current profiles for four-quadrant operations of DC machines. Based on Figure 3, when the load is a separately excited motor of constant field, the positive voltage and positive current in the first quadrant (Q1), rising the voltage that cause "forward drive" condition. While changing the polarity of both the armature voltage and the armature current resulting in a "reverse" drive in quadrant III (Q3). In quadrants II (Q2) and IV (Q4), the direction of energy flow is reversed and the motor operates as a generator braking rather than driving.

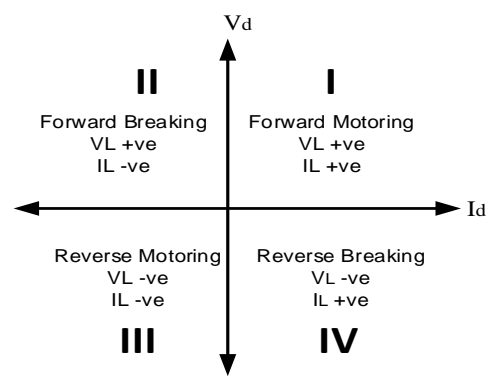

Figure 3. Four quadrant operation polarities 


\section{PROPOSED FOUR QUADRANT OPERATION OF DC TO DC CONVERTER}

The implementation of the SPMC as a DC chopper requires completely different bi-directional switching arrangements. It is depending on the desired operational requirements of the proposed four quadrant operations $[14,17,18]$. The magnitude of the converter's output voltage is controlled by PWM variations in duty cycle. The switching sequences are designed to follow Table 1. The dark arrow indicated that switch is turned-on and behaves as the power switching performing the required converter operation. The dotted line represents the safe-commutation switching during each particular state that is continuously turned-ON.

\subsection{First Quadrant Operation (Q1)}

For Q1 operation (forward motoring), the load voltage and current profiles is as shown in Figure 3. Based on the switching algorithm as tabulated in Table 1, switches S1a and S4a are turn-ON, allowing current to flow from the input source to the load and return back to the negative input source as illustrated in Figure 4(a). For the safe-commutation technique, switch S2b is turn-ON, when the switch S4a is turn-OFF. Through this technique, the energy stored in the inductive load could be commutated through switches S1a and S2b as illustrated in Figure 4(b). The switching algorithm for Q1 operation is shown in Figure 4(c).

Table 1. Switching Pattern for Four Quadrant DC to DC Converter

\begin{tabular}{ccccc}
\hline Switches & First Quadrant & Second Quadrant & Third Quadrant & Fourth Quadrant \\
\hline S1a & ON & OFF & OFF & OFF \\
S1b & OFF & ON & ON & OFF \\
S2a & OFF & OFF & ON & OFF \\
S2b & ON & OFF & PWM & ON \\
S3a & OFF & PWM & OFF & OFF \\
S3b & OFF & OFF & OFF & PWM \\
S4a & PWM & OFF & OFF & OFF \\
S4b & OFF & ON & & \\
\hline
\end{tabular}

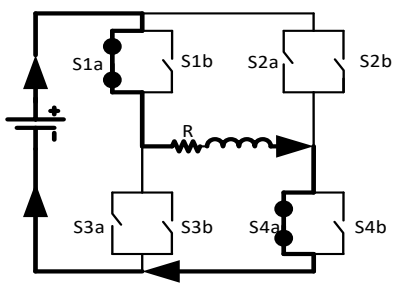

(a)

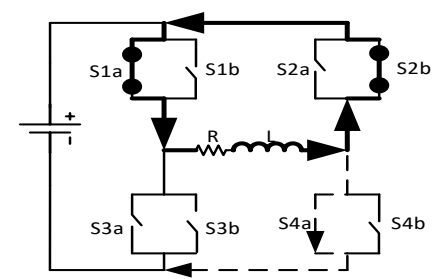

(b)

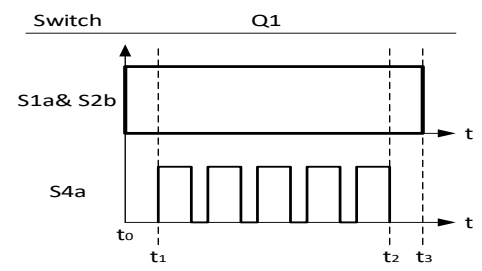

(c)

Figure 4. (a) Current flow for Q1, (b) Current flow with safe-commutation strategy and (c) Switching algorithm for Q1 operation

\subsection{Second Quadrant Operation (Q2)}

For Q2 operation, the load voltage and current profiles is as shown in Figure 3. Based on the switching algorithm as tabulated in Table 1, switches S1b and S4b are turn-ON, allowing current flow out of the load as illustrated in Figure 5(a). For the safe-commutation technique, switch S1b is turn-ON, while the switch S3a is turn-OFF. Through this technique, the energy stored in the inductive load can be commutated through switches S1b and S4b as illustrated in Figure 5b.

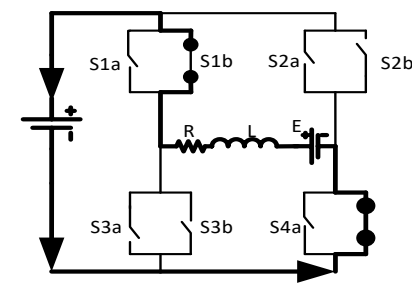

(a)

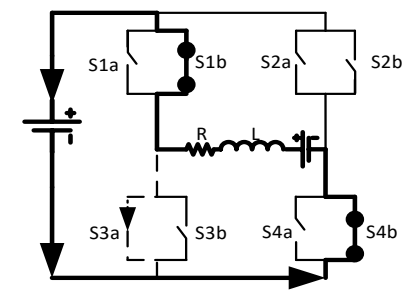

(b)

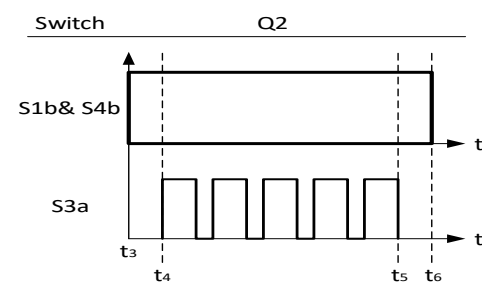

(c)

Figure 5. (a) Current flow for Q2 operation, (b) Current flow with safe-commutation strategy and (c) Switching algorithm for Q2 operation 


\subsection{Third Quadrant Operation (Q3)}

For Q3 operation, the load voltage and current profiles is as shown in Figure 3. Based on the switching algorithm as tabulated in Table 1, switches S2a and S3a are turn-ON, allowing current flow from the input source to the load and return back to the negative input source as illustrated in Figure 6(a). For the safe-commutation technique, switch S1b is turn-ON, when the switch S3a is turn-OFF. Through this technique, the energy stored in the inductive load can be commutated through switches S2a and S1b is illustrated in Figure 6(b).

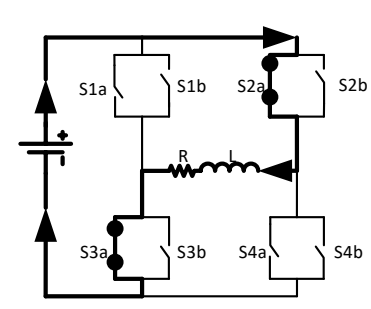

(a)

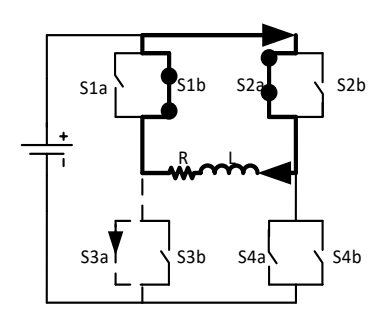

(b)

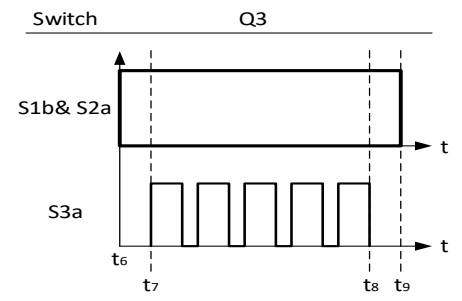

(c)

Figure 6. (a) Current flow for Q3, (b) Current flow with safe-commutation strategy and (c) Switching algorithm for Q3 operation

\subsection{Fourth Quadrant Operation (Q4)}

For Q4 operation, the load voltage and current profiles is as shown in Figure 3. Based on the switching algorithm as tabulated in Table 1, switches S2b and S3b are turn-ON, allowing current flow from the back EMF to the load and return back to the negative input of back EMF as illustrated in Figure 7(a). For the safe-commutation technique, switch S2b is turn-ON, when the switch S4a is turn-OFF. Through this technique, the energy stored in the inductive load could be commutated through switches $S 3 b$ and $S 2 b$ as illustrated in Figure 7(b).

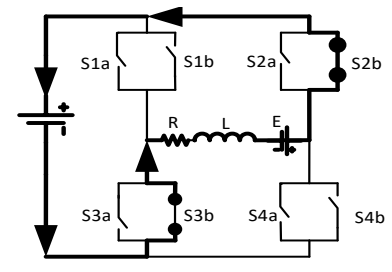

(a)

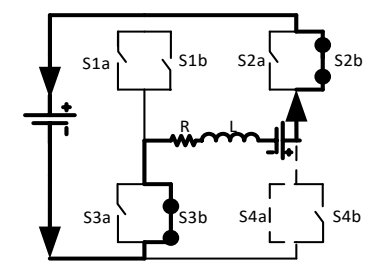

(b)

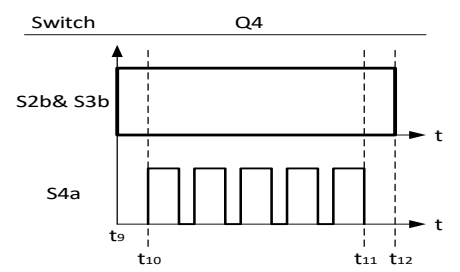

(c)

Figure 7. (a) Current flow for Q4, (b) Current flow with safe-commutation strategy and

(c) Switching algorithm for Q4 operation

\section{COMPUTER SIMULATION MODEL}

In this work, MATLAB/Simulink (MLS) is used to model and simulate the proposed circuit operation. The parameter used is as tabulated in Table 2. Figure 8 shows the top main model of the proposed converter in MLS. This block model included PWM generator, the controller and the SPMC switches. The output of the converter is controlled by PWM signal that was generated by comparing a triangle wave signal with an adjustable DC reference signal. Figure 9 shows the controller circuit while, Figure 10(a) shows the SPMC circuit model. Figure 10(b) shows the bidirectional switch cell module that use common emitter connection. The output of the SPMC is connected to the resistor and inductor to represent an inductive load.

Table 2. Parameters of the simulation model

\begin{tabular}{cc}
\hline Parameters & Value \\
\hline Input Source (DC) & $30 \mathrm{~V}$ \\
Sample Modulation Index $\left(m_{i}\right)$ & 0.75 \\
Inductance & $\mathrm{L}=0.004 \mathrm{H}$ \\
Resistance & $\mathrm{R}=50 \Omega$ \\
\hline
\end{tabular}




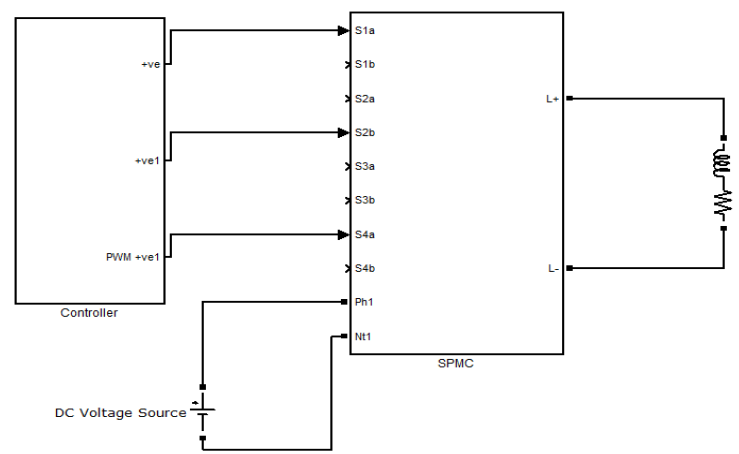

Figure 8. Top main model of converter in MLS

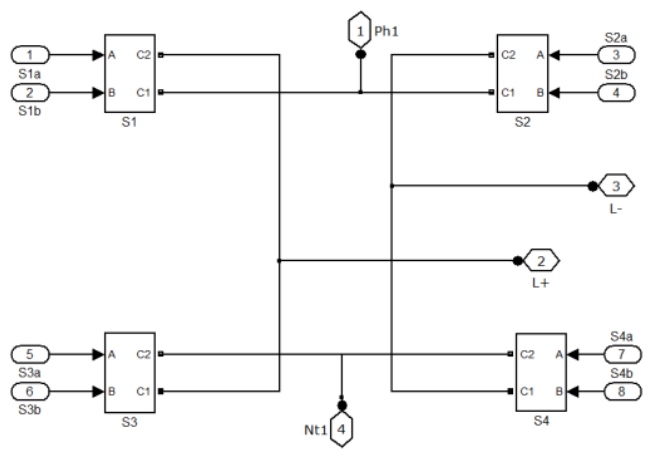

(a)

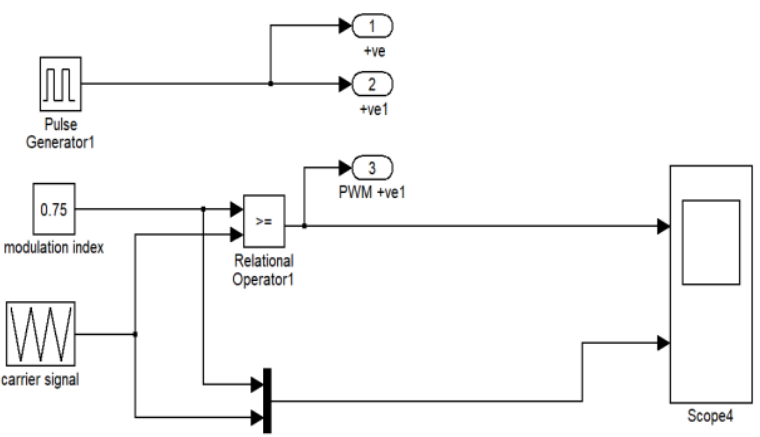

Figure 9. PWM model in MLS

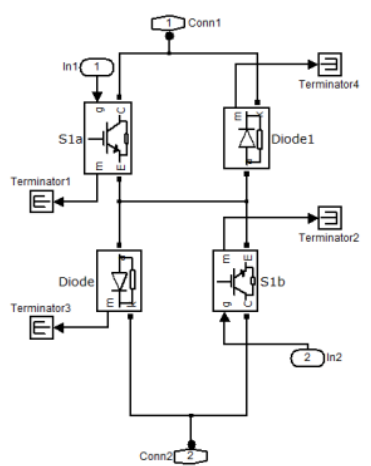

(b)

Figure 10. (a) SPMC circuit in MLS and (b) Bidirectional switch cell module

\section{RESULTS AND DISCUSSION}

\subsection{Resistive (R) Load}

Figures 11 and 12 show the output voltage and current waveforms for Q1 operation. For Q1 operation, the output voltage and current are positive to perform the forward motoring operation of DC drives. Figures 13 and 14 show the output voltage and current waveforms for Q2 operation. For Q2 operation, the output voltage is positive, while the output current is negative to perform the forward breaking operation of DC drives. Figures 15 and 16 show the output voltage and current waveforms for Q3 operation. As can be seen, for Q3 operation, the output voltage and current are negative to perform the reverse motoring operation of DC drives. Figures 17 and 18 show the output voltage and current waveforms for Q4 operation, where the output voltage is negative, while the output current is positive to perform the reverse breaking operation of DC drives.

\subsection{Inductive (RL) Loads without Safe-Commutation Strategy}

In this section, the effect of inductive (RL) loads is presented to show that without any safecommutation strategy in MCs, could lead to the output voltage and/or current spikes. Figures 19 and 20 show the output voltage and current waveforms for Q1 operation for inductive load without safe-commutation strategy. As can be seen in Figure 19, the spikes occurs due to the presents of the inductive load. This spike can cause a serious harmful to the proposed converter. For Q2 and Q4 operations, the spikes does not presents because there is a back EMF voltage connected in series with the inductor, thus, there is no change of current in inductive load occurs. Figures 21 and 22 show the output voltage and current waveforms for Q3 operation. As can be seen in Figures 21 and 22, the spikes occurs due to the presentation of the inductive load.

\subsection{Inductive (RL) Loads with Safe-Commutation Strategy}

This section presents results that have been obtained by implemented the proposed safecommutation strategy. Figures 23 and 24 show the output voltage and current waveforms of Q1 operation, while Figure 25 shows the output voltage waveform for Q3 operation for the inductive load with the 
proposed safe-commutation strategy. As can be seen, the present spikes as discussed in the previous section were successfully eliminated with the proposed safe-commutation strategy, thus, verify the workability and the effectiveness of the proposed safe-commutation strategy.

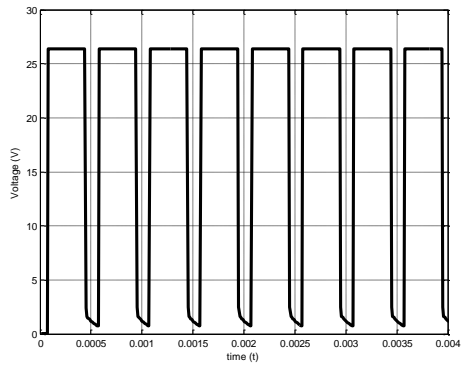

Figure 11. Output voltage for Q1 operation

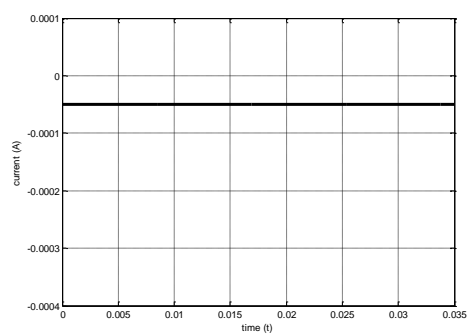

Figure 14. Output current for Q2 operation

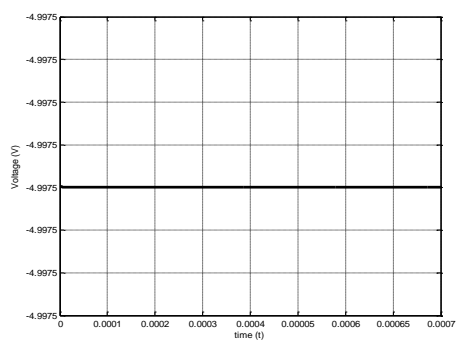

Figure 17. Output voltage for Q4 operation

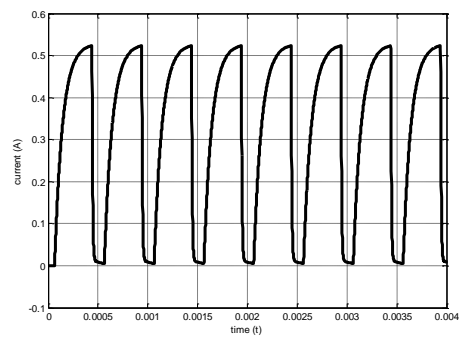

Figure 20. Output current for Q1 operation without safecommutation strategy

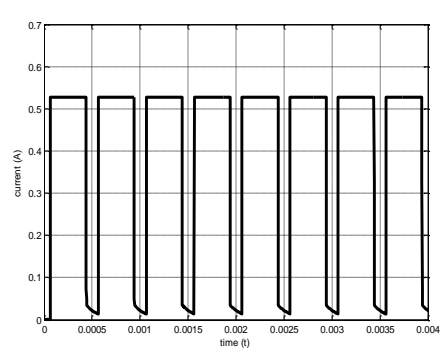

Figure 12. Output current for Q1 operation

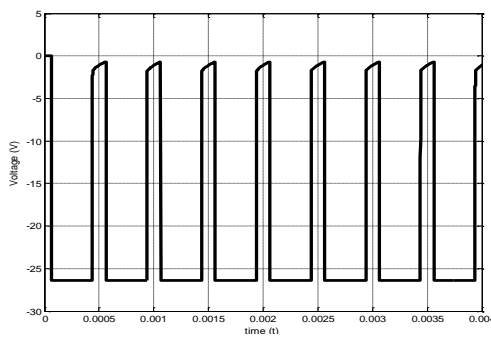

Figure 15. Output voltage for Q3 operation

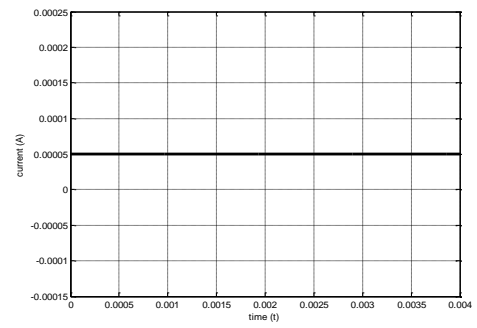

Figure 18. Output current for Q4 operation

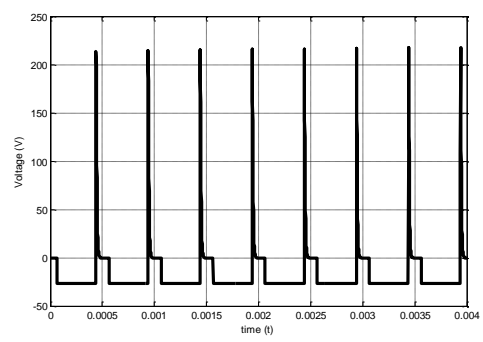

Figure 21. Output voltage for Q3 operation without safecommutation strategy

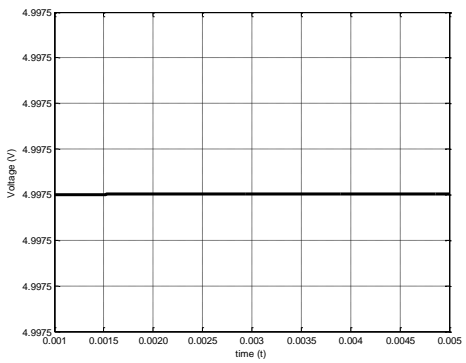

Figure 13. Output voltage for Q2 operation

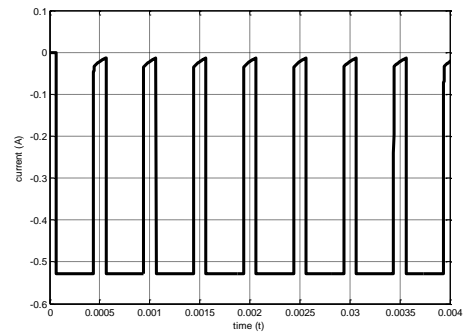

Figure 16. Output current for Q3 operation

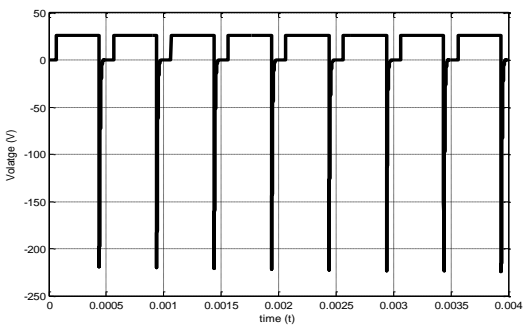

Figure 19. Output voltage for Q1 operation without safe-commutation strategy

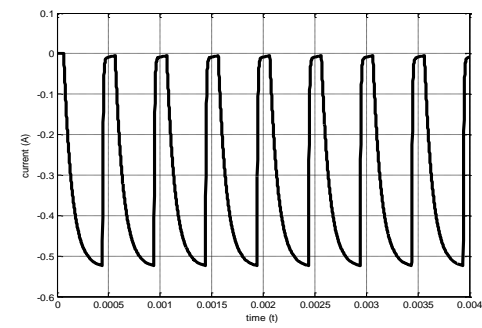

Figure 22. Output current for Q3 operation without safecommutation strategy 


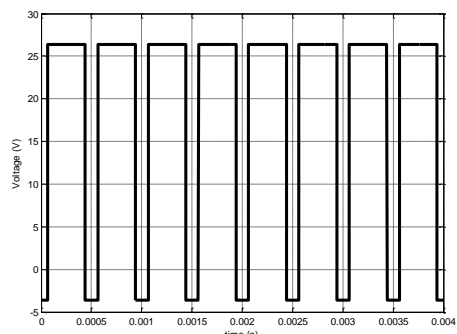

Figure 23. Output voltage for Q1 operation with safe-commutation strategy

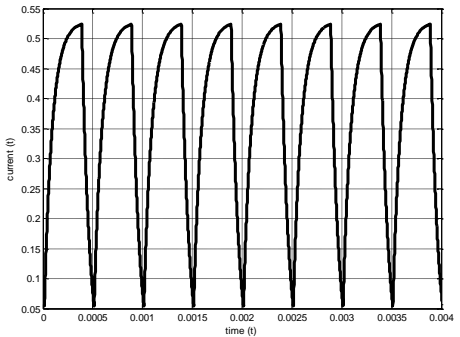

Figure 24. Output current for Q1 operation with safe-commutation strategy

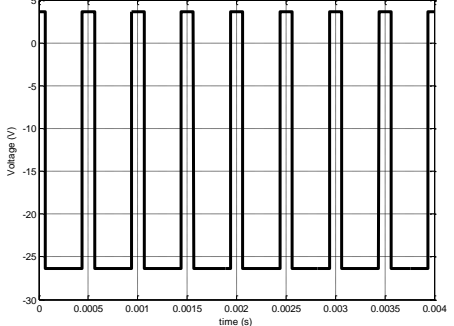

Figure 25. Output voltage for Q3 operation with safe-commutation strategy

\section{CONCLUSION}

In this paper, the operation of four quadrant DC to DC converter using SPMC has been verified. The presented results show that the voltage and current profiles for each quadrant are similar with the theoretical characteristics. The proposed safe-commutation technique have shown that the voltage or current spikes have been successfully eliminated, thus confirmed its workability. The use of the proposed circuit topology could remove the use of additional DC-DC chopper such as dual-converter to perform the four quadrant operation, hence, reduce the converter power loss and increase the power density of the power supply system.

\section{ACKNOWLEDGEMENTS}

Authors gratefully acknowledge the financial support from Ministries of Higher Education Malaysia and Institute of Research Management and Innovation (IRMI) Universiti Teknologi MARA Grant No: 600IRMI/MyRA 5/3/BESTARI (029/2017).

\section{REFERENCES}

[1] Xuefeng $\mathrm{Hu}$; Jianzhang Wang ; Linpeng Li ; Yongchao Li; "A Three-Winding Coupled-Inductor DC-DC Converter Topology With High Voltage Gain and Reduced Switch Stress", IEEE Transactions on Power Electronics, Volume: 33, Issue: 2, Page s: 1453 - 1462, Year: 2018.

[2] F. Pellitteri, V. Castiglia, P. Livreri, and R. Miceli, "Analysis and design of bi-directional DC-DC converters for ultracapacitors management in EVs," 2018 Thirteenth International Conference on Ecological Vehicles and Renewable Energies (EVER), Page s: 1 - 6, Year: 2018.

[1] C. Vlad, P. Lefranc, P. Rodriguez-Ayerbe, and E. Godoy, "Advanced control laws of DC-DC converters based on piecewise affine modelling. Application to a step-down converter," IET Power Electron., vol. 7, no. 6, pp. 1482-1498, 2014.

[2] A. A. Badeli, R. Baharom, N. Hidayat, and M. K. Hamzah, "Single-phase matrix converter with reduced switch count operating as buck or boost rectifier," ISCAIE 2012 - 2012 IEEE Symp. Comput. Appl. Ind. Electron., pp. 20-25, 2012.

[3] V. Scaini and T. O. M. MA, "High Current DC Chopper in the Metals Industry," Ind. Appl. Mag. IEEE, vol. 8, no. 2, pp. 26-33, 2002.

[4] L. Gyugyi, Static Power Frequency Changers: Theory, Performance, and Application. 1976.

[5] R. Baharom, H. Hashim, M. N. Seroji, and M. K. Hamzah, "A new single-phase dual converter using single-phase matrix converter," 2008 3rd IEEE Conf. Ind. Electron. Appl. ICIEA 2008, pp. 1151-1156, 2008.

[6] Divya Ahirrao et al, "Analysis of Single Phase Matrix Converter," Int. Journal of Engineering Research and Applications, vol. 4, no. 1, pp. 856-861, 2014.

[7] A. Zuckerberger, D. Weinstock, A. Alexandrovitz, and A. Alexand, "Single-phase matrix converter," IEE Proc. Electr. Power Appl., vol. 144, no. 4, p. 235, 1997.

[8] P. N. A. Megat Yunus, A. Jusoh, and M. K. Hamzah, "Passive damping network for a Single Phase Matrix Converter (SPMC) operating as a rectifier,” 2011 IEEE Symp. Ind. Electron. Appl. ISIEA 2011, pp. 173-177, 2011.

[9] P. K. Yadav and R. Dahiya, "Application of SPMC topology for single phase boost AC-AC and boost DC-DC converter," 2012 IEEE 5th Power India Conf. PICONF 2012, pp. 6-11, 2012.

[10] Z. Idris, M. K. Hamzah, and A. M. Omar, "Implementation of Single-Phase Matrix Converter as a Direct AC-AC Converter Synthesized Using Sinusoidal Pulse Width Modulation with Passive Load Condition," 2005 Int. Conf. Power Electron. Drives Syst., vol. 2, pp. 1536-1541.

[11] R. Baharom and M. K. Hamzah, "Advanced single-phase AC-DC converter using single-phase matrix converter topology incorporating with active power filter function," 2010 IEEE Int. Energy Conf. Exhib. EnergyCon 2010, pp. 108-113, 2010. 
[12] A. K. Sahoo, J. Meenakshe, S. S. Dash, and T. Thyagarajan, "Analysis and simulation of Matrix Converter Using PSIM," 7th Internatonal Conf. Power Electron. 2007. ICPE '07. pp. 414-419, 2008.

[13] P. N. A. M. Yunus, A. Jusoh, and M. K. Hamzah, "AC-DC Single Phase Matrix Converter with a constant power load (CPL),” 2012 IEEE Symp. Ind. Electron. Appl. ISIEA 2012, pp. 275-280, 2012.

[14] M. N. S. Z, A. R. N. F, M. K. Hamzah, "Single Phase Matrix Converter Operating as a Four Quadrant DC Chopper controlled using Xilinx FPGA," International Journal of Electrical and Electronic Systems Research, vol. 4, no. June, pp. 19-30, 2011.

[15] J. Ramirez-Hernandez, I. Araujo-Vargas, and M. Rivera, "A Modular AC-DC Power Converter with Zero Voltage Transition for Electric Vehicles,” Energies, vol. 10, no. 9, p. 1386, 2017.

[16] R. Kumar, A. V. Goyal, S. Srivastava, S. P. Singh, and N. Singh, "Modelling and Simulation of Matrix Converter Based DC-DC Converter," Energy Effic. Technol. Sustain. (ICEETS), 2013 Int. Conf., pp. 134-138, 2013.

[17] M. Vorobyov, "Overview of Single Phase Matrix Converter Application," Publ. Dr. Sch. Energy, vol. 3, pp. 201-207, 2011.

[18] S. Z. M. Noor, N. F. A. Rahman, and M. K. Hamzah, "Simulation of DC to DC Converter using Single Phase Matrix Converter topology,” 2010 IEEE Symp. Ind. Electron. Appl., ISIEA, pp. 149-154, 2010.

[19] M.F. Mohd Zin, R. Baharom, I. Mohd Yassin; "Development of Boost Inverter Using Single Phase Matrix Converter Topology", International Journal of Engineering \& Technology, Vol.: 7, No.: 3, Pages: 241-245, Year: 2018.

[20] Zafirah Zainuddin, Rahimi Baharom, Ihsan Mohd Yassin, Khairul Safuan Muhammad; "Solid-State Transformer (S2T) of Single Phase Matrix Converter", International Journal of Power Electronics and Drive Systems, Vol 9, No 3., Pages 997-1005, Year: 2018.

[21] Idris, A.; Baharom, R.; Hamzah, N.R.; Hamzah, M.K.; Mohd Salleh, M.K., "Studies on performance of Proportional Integral and Hysteresis Control in Current Control Loop for AC-DC converter using SPMC fed PMDC Motor," in 2014 IEEE International Conference on Power and Energy (PECon), vol., no., pp.354-359, 1-3 Dec. 2014

[22] Nagisa Takaoka; Hiroki Takahashi; Jun-ichi Itoh, "Isolated Single-Phase Matrix Converter Using Center-Tapped Transformer for Power Decoupling Capability", IEEE Transactions on Industry Applications, Volume: 54, Issue: 2, Page s: 1523 - 1531, Year: 2018.

[23] Yushan Liu; Weihua Liang; Baoming Ge; Haitham Abu-Rub; Ning Nie, "Quasi-Z-Source Three-to-Single-Phase Matrix Converter and Ripple Power Compensation Based on Model Predictive Control", IEEE Transactions on Industrial Electronics, Volume: 65, Issue: 6, Page s: 5146 - 5156, Year: 2018.

[24] Diogo Varajão; Rui Esteves Araújo; Luís Miguel Miranda; João A. Peças Lopes, "Modulation Strategy for a Single-Stage Bidirectional and Isolated AC-DC Matrix Converter for Energy Storage Systems", IEEE Transactions on Industrial Electronics, Volume: 65, Issue: 4, Page s: 3458 - 3468, Year: 2018.

[25] Lukas Schrittwieser; Patricio Cortés; Lukas Fässler; Dominik Bortis; Johann W. Kolar, "Modulation and Control of a Three-Phase Phase-Modular Isolated Matrix-Type PFC Rectifier", IEEE Transactions on Power Electronics, Volume: 33, Issue: 6, Page s: 4703 - 4715, Year: 2018. 